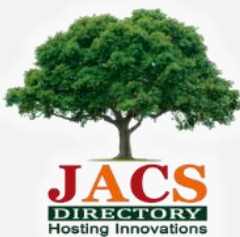

Journal of Nanoscience and Technology

\title{
Synthesis and Characterization of Nano Bioglass for the Application of Bone Tissue Engineering
}

\author{
Pawan Kumar1,*, Brijnandan S. Dehiya ${ }^{1}$, Anil Sindhu², Vinod Kumar ${ }^{3}$ \\ ${ }^{1}$ Department of Materials Science and Nanotechnology, Deenbandhu Chhotu Ram University of Science and Technology, Murthal - 131 039, Haryana, India. \\ ${ }^{2}$ Department of Biotechnology, Deenbandhu Chhotu Ram University of Science and Technology, Murthal - 131 039, Haryana, India. \\ ${ }^{3}$ Department of Bio and Nanotechnology, Guru Jambheshwar University of Science and Technology, Hisar - 125 001, Haryana, India.
}

\section{ARTICLE DETAILS}

\section{Article history:}

Received 11 July 2018

Accepted 27 July 2018

Available online 20 August 2018

\section{Keywords:}

Nanoparticles

Bioglass

Biodegradable

SBF

\begin{abstract}
A B S T R A C T
In this paper, we are addressing the development of new composition $\left(60 \% \mathrm{SiO}_{2}-30 \% \mathrm{CaO}-10 \% \mathrm{P}_{2} \mathrm{O}_{5}\right)$ of biodegradable and biocompatible bioglass (nBG) nanoparticles. The bioglass nanoparticles have been fabricated by sol-gel method. To get functionalized bioglass nanoparticles, they were treated with lysozyme $(1 \mathrm{mg} / \mathrm{mL})$ for $48 \mathrm{~h}$. Morphology of nanoparticles, such as structure, particle size, and surface topography were studied by TEM. Bioglass nanoparticles generate hydroxyapatite layer when nanoparticles treated with simulated body fluid (SBF) for 7 days. The presence of bioglass and hydroxyapatite phases confirmed by XRD. TEM images revealed irregular shaped with slightly agglomeration of nanoparticles in nanometer range (200 to $500 \mathrm{~nm}$ ). The in-vitro biodegradation of nanoparticles was confirmed by weight loss in the presence of SBF. The cytotoxicity effects and cell proliferation of respective sample were investigated through MTT assay. BET results revealed average surface area $\left(10.4 \mathrm{~m}^{2} / \mathrm{g}\right)$ of nanoparticles. The nano range of particles will provide better surface to volume ratio over micro or macro particles which makes them more effective so they are often able to react rapidly.
\end{abstract}

\section{Introduction}

Trauma, injury, infections and deterioration of bones are becoming human health threatening problems. Tissue Engineering eliminates issues like donor site morbidity, less availability, immunogenicity and infection causing microbes transfer $[1,2]$. The field of tissue engineering focuses on alternative treatment options through the combination of life science and engineering philosophies. The main bone tissue engineering attitudes are incorporation of specific cells and biomolecules (e.g. Growth factors, peptides, polysaccharides) in an incapacitated tissue [3]. The material's characteristics like biocompatibility, biodegradability, and mechanical characteristics depend on material's properties like, solubility, configuration, hydrophobicity/hydrophilicity, surface energy, water retaintion capacity and molecular weight. Engineered materials enhance cell adhesion, viability and proliferation with less toxicity. These materials mimic the extracellular matrix and have a crucial role to play in supporting cell growth, differentiation and in delivering growth factors or other bioactive molecules [4]. In 1969, Professor L. Hench invented first bioglass that could bond with bone. He fabricated a biodegradable glass system $\mathrm{Na}_{2} \mathrm{O}-\mathrm{CaO}-\mathrm{SiO}_{2}-\mathrm{P}_{2} \mathrm{O}_{5}$ with high calcium content [5]. After that several types of bioactive glass with different compositions synthesized. This launched field of bioactive glass ceramics, synthetic hydroxyapatite [6] and other calcium phosphate based materials [7]. Bioglass rapidly bonds with bone and makes bone-bioglass interface by the generation of hydroxyapatite (HA) layer on the dissolution of bioglass [8]. The dissolution of bioglass support osteoinduction. The presence of silica and calcium ions stimulate osteogenic cells to mimic bone matrix that leads to natural bone repair [9]. Bioactive glasses are using in healing of defected or diseased bones. Bioactive glass is also using for the coating of metallic implants asuch as hip prosthesis and peridontal. Coating have potential to increase compatibility and stability [10]. The generation of HA layer make bond with collagen fibrils of defected tissue. This bonding involve attachment of bone progenitor cells, cell differentiation, amalgamation of collagen fibrils, and excreation of ECM that is followed by its mineralization which leads to osteogenesis [9]. The ability of biogalss to generate HA layer was confirmed in simulated body fluid (SBF). This in-

\section{*Corresponding Author:pawankamiya@yahoo.in(Pawan Kumar)}

vitro study taken as an sign of bioactivity of synthesized bioactive glass [6, 11]. The main goal of this study was to fabricate biodegradable and biocompatible bioglass nanoparticles.

\section{Experimental Methods}

\subsection{Materials}

The analytical grade (AR) chemicals were procured for this research work. Tetraethyl orthosilicate (TEOS), phosphorus pentoxide $\left(\mathrm{P}_{2} \mathrm{O}_{5}\right)$, calcium nitrate tetra hydrate $\left(\mathrm{Ca}\left(\mathrm{NO}_{3}\right)_{2} .4 \mathrm{H}_{2} \mathrm{O}\right)$, di-ammonium hydrogen phosphate $\left.\left(\mathrm{NH}_{4}\right)_{2} \mathrm{HPO}_{4}\right)$, ammonium hydroxide $\left(\mathrm{NH}_{4} \mathrm{OH}\right)$, sodium hydroxide $(\mathrm{NaOH})$, acetic acid $\left(\mathrm{CH}_{3} \mathrm{COOH}\right)$ and chitosan were purchased from Sigma-Aldrich. Glutaraldehyde was procured from TCI chemicals. Lysozyme and ethanol were purchased from Thermo Fisher Scientific.

\subsection{Synthesis of Bioglass (60\% $\left.\mathrm{SiO}_{2}-30 \% \mathrm{CaO}-10 \% \mathrm{P}_{2} \mathrm{O}_{5}\right)$ Nanoparticles}

The novel composition of bioglass was fabricated by using sol-gel method.

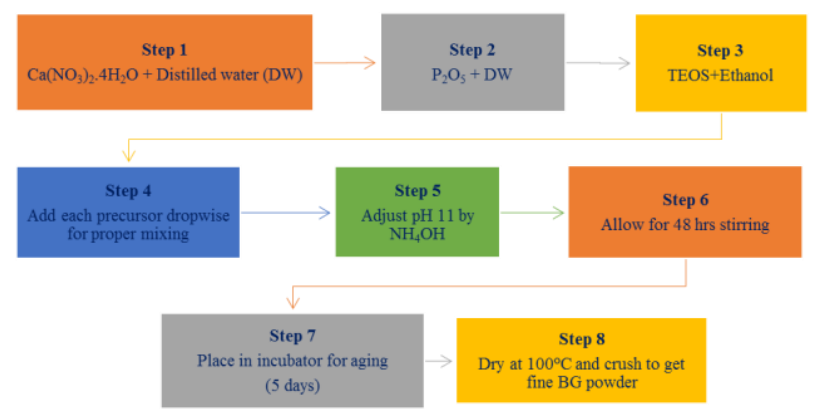

Fig. 1 Bioglass nanoparticles synthesis

The amount of TEOS (4.054 g) mixed with ethanol and kept on a magnetic stirrer for proper mixing for an hour at room temperature. During this, calcium nitrate tetra hydrate $(2.372 \mathrm{~g})$ and phosphorus pent oxide $(0.267 \mathrm{~g})$ were dissolved in distilled water separately and left on magnetic stirrer for 30 minutes also at room temperature. After an hour, 
calcium containing solution was added to the solution of TEOS dropwise. After that phosphorus containing solution also added to this suspension. Use ammonia solution to maintain $\mathrm{pH} 11$ of the solution. Transfer the solution to an incubator and kept for 48 hours for aging in order to obtain the gel. The gel was placed in an oven at $100{ }^{\circ} \mathrm{C}$ for drying to eliminate ethanol. The dried sample was stored in airtight container for further characterization.

\subsection{XRD Analysis}

The synthesis of bioglass was confirmed by phase identification in XRD (Rigaku Ultima IV). The powdered nanoparticles were scanned in between the range of 15 to 60 degree which provide information in the form of $x-y$ plot (intensity vs $2 \theta$ ).

\subsection{FTIR Analysis}

It was used to identify the presence of different functional groups in the sample. The spectrums of nano BG, was recorded within the frequency range of $4000 \mathrm{~cm}^{-1}$ to $400 \mathrm{~cm}^{-1}$ by Perkin Elmer Frontier FTIR. The resultant spectrum shown the compositional information such as chemical groups, ions and bonding vibrations.

\subsection{TEM Analysis}

The morphology of powdered nBG was analysed by TEM, Tecnai. TEM provide the molecular level information of samples such as particles distribution, shape, size and particles interactions at nanoscale. The good quality 2-D black and white images were generated that exhibited detailed morphology of samples.

\subsection{BET Analysis}

The Brunauer, Emmett and Teller (BET) technique was used to measure the surface area of nanoparticles. The well-defined surface areas is beneficial in tissue engineering. The high surface will help in cells attachment or proliferation. The adsorption and desorption will occur during analysis that give a slope and intercept which give information of surface area.

\subsection{Functionalization of Bioglass}

Bioglass nanoparticles were mixed with distilled water at a concentration of $10 \mathrm{mg} / \mathrm{mL}$. The lysozyme $(1 \mathrm{mg} / \mathrm{mL})$ was dissolved in this mixture solution. After that bioglass suspension was then mixed with lysozyme solution. Diluted ammonia hydroxide was used to adjust the $\mathrm{pH}$ 10 of suspension. After centrifugation and three times washing with distilled water, functionalized nanoparticles were collected [12].

\subsection{In-Vitro Bioactivity}

The bioactivity of materials depends upon various factors including composition and morphology. The simulated body fluid (SBF) was used for the measurement of bioactivity of nano bioglass. The samples were incubated in SBF at $37{ }^{\circ} \mathrm{C}$ for 7 days. Because SBF consist of nearly same concentration of inorganic constituents as specified in blood plasma [13]. The bioactivity of a material confirm after 7 days when apatite formation start on the surface of the nanoparticles[14] that was analysed by XRD. Then materials starts to dissolve and releasing ions in the tissue fluids that directly affect the function of bone cell $[11,15]$.

\subsection{In-Vitro Biodegradation}

The bioglass nanoparticles were sterilized by UV light befor the test performed. The degradation investigation of bioglass nanoparticles was performed in SBF. Initially the weight of dry samples was recorded. After predefined time intervals ( 3 and 7 days), the sample was retrieved, rinsed three time with distilled water and dried. Then the difference in weight was noted in percentage and calculated by using Eq.(1) [16-18]:

Weight degraded $(\%)=\frac{W_{f}-W_{0}}{W_{0}} \times 100$

Where, $W_{0}$ is initial and $W_{\mathrm{f}}$ is final weight after incubation of sample.

\subsection{Cell Culture Studies}

To check the cytotoxicity and biocompatibility of nano bioglass, Fibroblast cell lines were maintained in the cell culture facility in MEM with $10 \%$ FBS and $100 \mathrm{U} / \mathrm{mL}$ penicillin-streptomycin. Before cell seeding, all the samples were sterilized and placed in an incubator with cell culture for 2 hours with $5 \% \mathrm{CO}_{2}$ and $85 \%$ humidity. The detached cells $\left(1 \times 10^{5}\right.$ cells/100 $\mu \mathrm{L}$ ) were seeded dropwise on the surface of samples for the investigation of cytocompatibility. The cell seeded samples placed in a humidified incubator at $37^{\circ} \mathrm{C}$ for $4 \mathrm{~h}$ for the cell attachment [19].

https://doi.org/10.30799/jnst.127.18040503

\section{Results and Discussion}

The FTIR spectrum (Fig. 2) revealed the presence of Si-O-Si group at 457 and $1093 \mathrm{~cm}^{-1}[20,21]$ and P-O group at $589 \mathrm{~cm}^{-1}$. The peak present at $3655 \mathrm{~cm}^{-1}$ reaveled presence of variable $\mathrm{OH}$ and $\mathrm{Si}-\mathrm{O}-\mathrm{H}$ groups. The chracteristic peak of $\mathrm{HPO}_{4}{ }^{2-}$ is present at $1652 \mathrm{~cm}^{-1}$ [20]. The presence of $\mathrm{N}-\mathrm{H}$ amide II bond confirmed at $1506 \mathrm{~cm}^{-1}$ [22]. The broad peak inside 900 to $1300 \mathrm{~cm}^{-1}$ were mainly known for the phosphate absorptions [23].

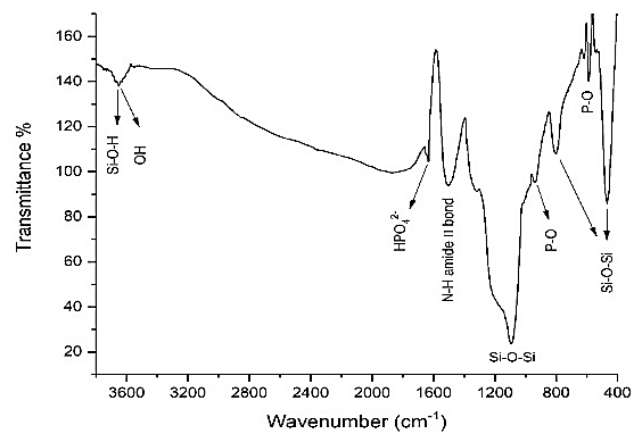

Fig. 2 FTIR spectrum of nano bioglass

The broad peak of XRD pattern as shown in image (Fig. 3) confirmed the synthesis of bioglass nanoparticles. The broad peak $\left(2 \theta=20^{\circ}\right.$ to $\left.30^{\circ}\right)$ clearly demonstrated the bioglass presence in XRD pattern. After the heat treatment at $400{ }^{\circ} \mathrm{C}$ for $2 \mathrm{~h}$, sample shown almost amorphous nature and this amorphous nature indicated glassy nature of the sample. If the nature of bioglass changed from amorphous to crystalline; bioactivity of will be decreased [24, 25] and mechanical properties increased [26]. The presence of silica in bioglass helps in the calcification of bone, cross-linking and resiliency of connective tissue [27].

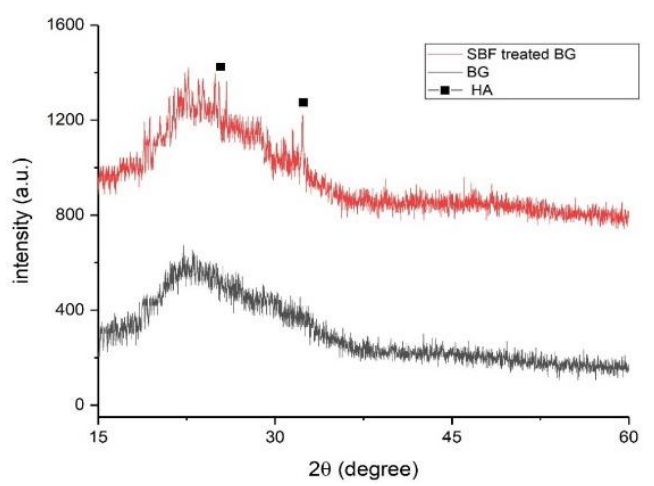

Fig. 3 XRD patteren of nano bioglass and SBF treated bioglass

$\mathrm{Ca}$ and $\mathrm{P}$ are essential consituients for muscle contraction and membrane permeability. The sol-gel derived bioglass having lower melting point, higher solubility which is benificial for the bioactivity [28]. The bioglass nanoparticles shown good compatibility in SBF through interfacial and cell mediated reactions [29]. In SBF solution biogalss starts to degrade and convert to appatite like structure at $37{ }^{\circ} \mathrm{C}[30,31]$. The generation of hydroxyapatite layer was checked by XRD as shown in Fig. 2 . The new peaks of hydroxyapatite were observed at $2 \theta=25^{\circ}$ and $2 \theta=$ $32^{\circ}$ standaradized by JCPDS card no. 09-0432. The XRD result confirmed that bioglass nanoparticles may induce a hydroxyapatite layer in SBF within 7 days. Higher surface area of nanoparticles may provide more space for the interaction between SBF and bioglass nanoparticles. This is consistent with the known superiority of bioactive glass in their in vitro bone-forming bioactivity. This hydroxyapatite layer is pseudomorphic [32] and formation of this layer increased with increasing SBF soaking time duration [33]. Physiochemical composition of the bioglass may play significant roles during the apatite growth process. The presnece of $\mathrm{Si}$ support osteoblast proliferation and differentition, bone mineralization with gene activation [34-36]. Hydroxyapatite is considered as an osteoconductive material and it promote new tissue growth and boneimplant interface [9]. Besides, it has been proposed that the in-vitro bioactivity is a signal of the bioactive potential of a material in-vivo [37]. The average surface area of bioglass nanoparticles was found $10.4 \mathrm{~m}^{2} / \mathrm{g}$, measured by BET with $\mathrm{N}_{2}$.

The TEM images (Fig. 4) of bioglass nanoparticles revealed irregular shape at nano and micro scale somewhat agglomeration in sample. The size of particles found almost $200 \mathrm{~nm}$. TEM image reveaaled particle size of bioglass vary from 200 to $500 \mathrm{~nm}$. As the size of particles increase, surface area of particles will be reduced. 


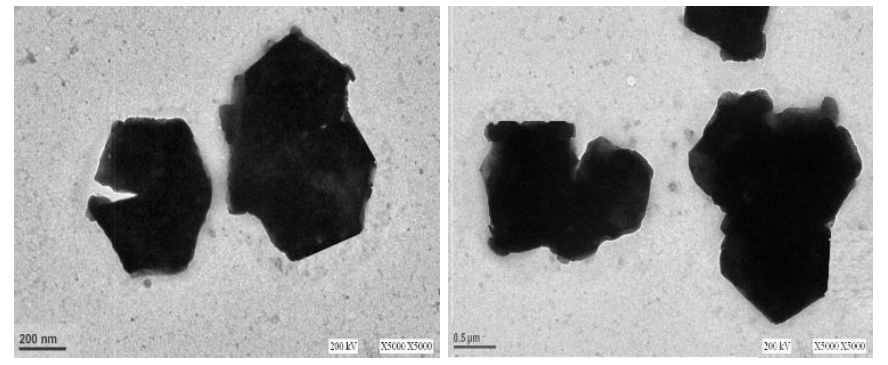

Fig. 4 TEM images of bioglass particles

The in-vitro weight degradation of bioglass nanoparticles found $12.5 \%$ after 3 days and $25.8 \%$ after 7 days of incubation. The degradation of bioglass may be taking place along with water ion usually in volatile phases. It may also depends on the degree of crystallinity, which controls the hydrolysis rate. In the presence of SBF, bioglass starts to dissolve and release ions. The lysozyme activated nanoparticles exhibited dosedependent antibacterial properties [12] within $24 \mathrm{~h}$. They also produce cytotoxicity against human hepatocellular carcinoma (HepG2) cell line [12]. The nano bioglass did not show any influence on fibroblast proliferation. After pre-selected time intervals (7 and 14 days) number of cells increasing as shown in Figs. 6 and 7. Fibroblast cells were successfully grown on the surface of bioglass nanoparticles.

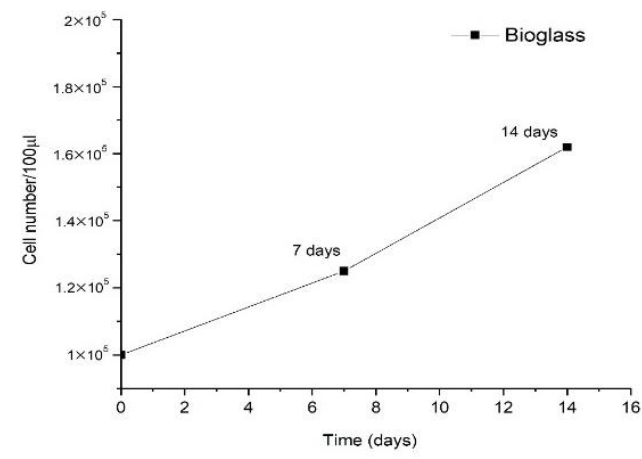

Fig. 5 Fibroblast growth on bioglass

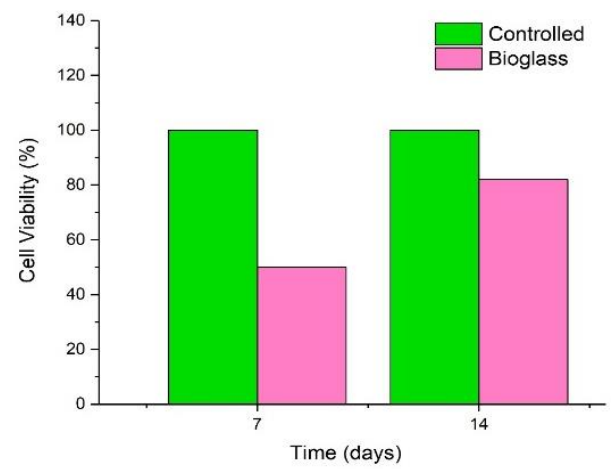

Fig. 6 Percentage growth of fibroblast w.r.t. time sample

\section{Conclusion}

In this work, a new composition $\left(60 \% \mathrm{SiO}_{2}-30 \% \mathrm{CaO}-10 \% \mathrm{P}_{2} \mathrm{O}_{5}\right)$ of biogalss was sucessfully fabricated. White coloured biodegradable and biocompatible amorphous bioglass nanoparticles were synthesized by solgel method. TEM image shows irregular shaped nanoparticles of 200 to $500 \mathrm{~nm}$. During in-vitro study, hydroxyapatite layer generation after soaking SBF prove the biocompatibility of nanoparticles. The MTT assay results confirmed the bioactivity of bioglass nanopaticles with respect to fibroblast cells. The fibroblast cells were sucessfully grown in the presence of bioglass nanoparticles. The dose dependent functionalized nanoparticles may also produce antimicrobial effects in bone tissue engineering applications. The presence of silica reduces the degradation rate of bioglass. Thus, Bioglass nanoparticles may paly a crucial role in some cases of damaged bone tissue regeneration.

\section{References}

[1] F. Anagnostou, R. Bizios, H. Petite, Engineering bone : challenges and obstacles, J. Cell. Mol. Med. 9 (2005) 72-84.
[2] D.W. Hutmacher, Scaffold design and fabrication technologies for engineering tissues- state of the art and future perspectives, J. Biomater. Sci. Polym. Ed. 12 (2001) 107-124.

[3] H. Chen, C.V.A.N. Blitterswijk, L. Moroni, Fabrication of nanofibrous scaffolds for tissue engineering applications, Woodhead Publ. Online, UK, 2013.

[4] A.M. Martins, C.M. Alves, F. Kurtis Kasper, A.G. Mikos, R.L. Reis, Responsive and in situ-forming chitosan scaffolds for bone tissue engineering applications: an overview of the last decade, J. Mater. Chem. 20 (2010) 1638-1645.

[5] L.L. Hench, The story of Bioglass®, J. Mater. Sci. Mater. Med. 17 (2006) $967-$ 978.

[6] T. Kokubo, Bioactive glass ceramics : properties and applications, Biomater. 12 (1991) 155-163.

[7] R.Z. Legeros, Properties of osteoconductive biomaterials: Calcium phosphates, Clin. Orthop. Relat. Res. 395 (2002) 81-98.

[8] T.K. Hench, L.L. Splinter, R.J. Allen, W.C. Greenlee, Bonding mechanisms at the interface of ceramic prosthetic materials, J. Biomed. Mater. Res. 5 (1971) 117 141.

[9] L.L. Hench, J.M. Polak, Third-generation biomedical materials, Sci. 295 (2002) 1014-1017.

[10] S.J. Gomez-Vega, J.M. Saiz, E. Tomsia, A.P. Oku, T. Suganuma, K. Marshall, G.W. Marshall, Novel bioactive functionally graded coatings on $\mathrm{Ti}_{6} \mathrm{Al}_{4} \mathrm{~V}, \mathrm{Adv}$. Mater. 12 (2000) 894-898.

[11] P. Ducheyne, Q. Qiu, Bioactive ceramics : the effect of surface reactivity on bone formation and bone cell function, Biomater. 20 (1999) 2287-2303.

[12] K. Zheng, M. Lu, Y. Liu, Q. Chen, N. Taccardi, N. Hüser, A.R. Boccaccini, Monodispersed lysozyme-functionalized bioactive glass nanoparticles with antibacterial and anticancer activities, Biomed. Mater. 11 (2016) 035012-1-13.

[13] T. Kokubo, H. Takadama, How useful is SBF in predicting in vivo bone bioactivity?, Biomater. 27 (2006) 2907-2915.

[14] A. El-Ghannam, C.Q. Ning, Effect of bioactive ceramic dissolution on the mechanism of bone mineralization and guided tissue growth in vitro, J. Biomed. Mater. Res. A 76 (2006) 386-397.

[15] A.M. Pietak, J.W. Reid, M.J. Stott, M. Sayer, Silicon substitution in the calcium phosphate bioceramics, Biomater. 28 (2007) 4023-4032.

[16] P. Kumar, B.S. Dehiya, A. Sindhu, Comparative study of chitosan and chitosangelatin scaffold for tissue engineering, Int. Nano Lett. 7 (2017) 285-290.

[17] K.C. Kavya, R. Jayakumar, S. Nair, K.P. Chennazhi, Fabrication and characterization of chitosan/gelatin $/ \mathrm{nSiO}_{2}$ composite scaffold for bone tissue engineering, Int. J. Biol. Macromol. 59 (2013) 255-263.

[18] J.A. Sowjanya, J. Singh, T. Mohita, S. Sarvanan, A. Moorthi, N. Srinivasan, N. Selvamurugan, Biocomposite scaffolds containing chitosan/alginate/nanosilica for bone tissue engineering, Colloid. Surf. B Biointerf. 109 (2013) 294 300.

[19] M. Peter, B. Nelson Sathy, S.V. Nair, N. Selvamurugan, H. Tamura, J. Rangasamy, Novel biodegradable chitosan-gelatin/nano-bioactive glass ceramic composite scaffolds for alveolar bone tissue engineering, Chem. Eng. J. 158 (2010) 353361.

[20] Y. Li, S. Cai, G. Xu, S. Shen, M. Zhang, T. Zhang, X. Sun, Synthesis and characterization of a phytic acid/mesoporous $45 S 5$ bioglass composite coating on a magnesium alloy and degradation behavior, RSC Adv. 5 (2015) 2570825716.

[21] H.S. Costa, A.A.P. Mansur, M.M. Pereira, H.S. Mansur, Engineered hybrid scaffolds of poly (vinyl alcohol)/ bioactive glass for potential bone engin eering applications : synthesis, characterization, cytocompatibility, and degradation, J. Nanomater. 2012 (2012) 1-16.

[22] M. Mehdipour, A. Afshar, M. Mohebali, Electrophoretic deposition of bioactive glass coating on 316L stainless steel and electrochemical behavior study, Appl Surf. Sci. J. 258 (2012) 9832-9839.

[23] L. Adams, E.R. Essien, R.O. Shaibu, A. Oki, Sol-gel synthesis of $\mathrm{SiO}_{2}-\mathrm{CaO}-\mathrm{Na}_{2} \mathrm{O}$ $\mathrm{P}_{2} \mathrm{O}_{5}$ bioactive glass ceramic from sodium metasilicate, New J. Glas. Ceram. 3 (2013) 11-15

[24] O.P. Filho, G.P. La Torre, L.L. Hench, Effect of crystallization on apatite-layer formation of bioactive glass 45S5, J. Biomed. Mater. Res. 30 (1996) 509-514.

[25] A. Chen, Q. Boccaccini, Coupling mechanical competence and bioresorbability in Bioglass ${ }^{\circledR}$-derived tissue engineering scaffolds, Adv. Eng. Mater. 8 (2006) 285-289.

[26] P. Li, Q. Yang, F. Zhang, The effect of residual glassy phase in a bioactive glassceramic on the formation of its surface apatite layer in vitro, J. Mater. Sci. Mater. Med. 3 (1992) 452-456.

[27] K. Schwarz, A bound form of silicon in glycosaminoglycans and polyuronides, Proc. Natl. Acad. Sci. USA 70 (1973) 1608-1612.

[28] R.L. Siqueira, O. Peitl, E.D. Zanotto, Gel-derived $\mathrm{SiO}_{2}-\mathrm{CaO}-\mathrm{Na}_{2} \mathrm{O}-\mathrm{P}_{2} \mathrm{O}_{5}$ bioactive powders: Synthesis and in vitro bioactivity, Mater. Sci. Eng. C 31 (2011) 983991.

[29] J. Chevalier, L. Gremillard, Ceramics for medical applications: A picture for the next 20 years, J. Eur. Ceram. Soc. 29 (2009) 1245-1255.

[30] W. Huang, D.E. Day, K. Kittiratanapiboon, M.N. Rahaman, Kinetics and mechanisms of the conversion of silicate (45S5), borate, and borosilicate glasses to hydroxyapatite in dilute phosphate solutions, J. Mater. Sci. Mater. Med. 17 (2006) 583-596.

[31] W. Huang, M.N. Rahaman, D.E. Day, Y. Li, Mechanisms for converting bioactive silicate, borate, and borosilicate glasses to hydroxyapatite in dilute phosphate solution, Phys. Chem. Glas. - Eur. J. Glas. Sci. Technol. Part B 47 (2006) 647-658.

[32] R.F. Fu, Q. Rahaman, M.N. Bal, B.S. Bonewald, L.F. Kuroki, K. Brown, Silicate borosilicate, and borate bioactive glass scaffolds with controllable degradation rate for bone tissue engineering applications. II. In vitro and in vivo biological evaluation, J. Biomed. Mater. Res. Part A 95A (2010) 172-179.

[33] C.V. Ragel, M. Vallet-Regí, L.M. Rodríguez-Lorenzo, Preparation and in vitro bioactivity of hydroxyapatite/solgel glass biphasic material, Biomater. 23 (2002) 1865-1872. 
[34] I.D. Xynos, M.V.J. Hukkanen, J.J. Batten, L.D. Buttery, L.L. Hench, J.M. Polak, Bioglass@45S5 stimulates osteoblast turnover and enhances bone formation in-vitro: Implications and applications for bone tissue engineering, Calcif. Tissue Int. 67 (2000) 321-329.

[35] I.D. Xynos, A.J. Edgar, L.D.K. Buttery, L.L. Hench, J.M. Polak, Ionic products of bioactive glass dissolution increase proliferation of human osteoblasts and induce insulin-like growth factor II mRNA expression and protein synthesis, Biochem. Biophys. Res. Commun. 276 (2000) 461-465.

[36] I.D. Xynos, A.J. Edgar, L.D.K. Buttery, L.L. Hench, J.M. Polak, Gene-expression profiling of human osteoblasts following treatment with the ionic products of Bioglass $\AA^{2} 45 S 5$ dissolution, J. Biomed. Mater. Res. 55 (2001) 151-157.

[37] P. Ducheyne, Bioceramics: material characteristics versus in vivo behavior, J. Biomed. Mater. Res. 21 (1987) 219-236. 